\title{
Molecular Imaging in Multiple Myeloma-Novel PET Radiotracers Improve Patient Management and Guide Therapy
}

\begin{abstract}
Johannes von Hinten ${ }^{1}$, Malte Kircher ${ }^{1}$, Alexander Dierks ${ }^{1}$, Christian H. Pfob ${ }^{1}$, Takahiro Higuchi 2,3, Martin G. Pomper ${ }^{4}$, Steven P. Rowe ${ }^{4}$, Andreas K. Buck ${ }^{2}$, Samuel Samnick ${ }^{2}$, Rudolf A. Werner ${ }^{2+}$ and Constantin Lapa ${ }^{1 \times+}$

${ }^{1}$ Nuclear Medicine, Faculty of Medicine, University of Augsburg, Augsburg, Germany, ${ }^{2}$ Department of Nuclear Medicine, University Hospital Würzburg, Würzburg, Germany, ${ }^{3}$ Graduate School of Medicine, Dentistry and Pharmaceutical Sciences, Okayama University, Okayama, Japan, ${ }^{4}$ The Russell H. Morgan Department of Radiology and Radiological Science, Johns Hopkins University School of Medicine, Baltimore, MD, United States
\end{abstract}

OPEN ACCESS

Edited by:

Antonia Dimitrakopoulou-Strauss, German Cancer Consortium, German

Cancer Research Center

(DKFZ), Germany

Reviewed by:

Domenico Albano,

University of Brescia, Italy

*Correspondence:

Constantin Lapa

constantin.lapa@uk-augsburg.de

tThese authors have contributed equally to this work

Specialty section:

This article was submitted to PET and SPECT,

a section of the journal

Frontiers in Nuclear Medicine

Received: 25 October 2021 Accepted: 01 February 2022 Published: 25 February 2022

Citation: von Hinten J, Kircher M, Dierks A Pfob CH, Higuchi T, Pomper MG, Rowe SP, Buck AK, Samnick S,

Werner RA and Lapa C (2022)

Molecular Imaging in Multiple Myeloma-Novel PET Radiotracers Improve Patient Management and Guide Therapy.

Front. Nucl. Med. 2:801792. doi: 10.3389/fnume.2022.801792
Due to its proven value in imaging of multiple myeloma (MM), including staging, prognostication, and assessment of therapy response, 2-deoxy-2-[18 Fffluoro-D-glucose (FDG) positron emission tomography (PET) is utilized extensively in the clinic. However, its accuracy is hampered by imperfect sensitivity (e.g., so-called FDG-negative MM) as well as specificity (e.g., inflammatory processes), with common pitfalls including fractures and degenerative changes. Novel approaches providing a read-out of increased protein or lipid membrane syntheses, such as $\left[{ }^{11} \mathrm{C}\right]$ methionine and $\left[{ }^{11} \mathrm{C}\right]$ choline or the $\mathrm{C}-\mathrm{X}-\mathrm{C}$ motif chemokine receptor 4-targeting radiotracer [ $\left.{ }^{68} \mathrm{Ga}\right]$ Pentixafor, have already been shown to be suitable adjuncts or alternatives to FDG. In the present focused review, those imaging agents along with their theranostic potential in the context of MM are highlighted.

Keywords: [18F]fluorodeoxyglucose, [C11]methionine, [C11]choline, [68Ga]Pentixafor, [177Lu]Penthixather, CXCR4, theranostics

\section{INTRODUCTION}

Multiple myeloma (MM) is defined by neoplastic cell proliferation in the bone marrow and by the overproduction of monoclonal antibodies or paraproteins (1). As an orphan disease, $1 \%$ of all cancer patients and $10 \%$ of all hematologic malignancies are attributable to MM $(2,3)$. Diagnosis is established based on the recommendations of the International Myeloma Working Group (IMWG) criteria, which are characterized by bone marrow infiltration, monoclonal proteins in body fluids (e.g., serum or urine), and osseous or renal damage (4). Magnetic resonance imaging (MRI) is the reference for detection for involvement of bone marrow and is recommended by the IMWG if prior screening with whole-body computed tomography (CT) does not provide a sufficient readout of osteolytic bone lesions (5). For instance, as recently demonstrated in a prospective setting, $\mathrm{MRI}$ and positron emission tomography/computed tomography with 2-deoxy-2-[ $\left.{ }^{18} \mathrm{~F}\right]$ fluoro-Dglucose (FDG PET/CT) were comparable for assessing bone lesions (6). Relative to PET, however, MRI identifies more diffuse bone lesions, whereas the tracer-based imaging technique is better suited to assess treatment response (6-8). Thus, as it can assess both bone marrow infiltration and extramedullary disease sites, the IMWG recommends FDG PET/CT, not only for suspected disease, but also in relapse or refractory scenarios (9). 
In this regard, FDG is considered a work-horse in MM, in particular as it can identify on-going disease (9). As such, FDG PET/CT can assess therapeutic efficacy and the identification of patients at risk of therapeutic failure, e.g., after novel agent-based induction therapy and subsequent double autotransplantation (10). For instance, Sachpekidis et al. investigated 48 treatment-naïve MM patients which underwent FDG PET in a prospective setting prior to autologous stem cell transplantation. Various quantitative and qualitative PETbased parameters could differentiate between high- vs. low-risk individuals. Patients with pathological scan findings on a visual assessment or increased maximum standardized uptake values had shorter progression-free survival (11).

Despite its usefulness in various clinical scenarios, and availability at virtually every PET center, FDG suffers from various drawbacks. For instance, false negative results may occur in low hexokinase-2 expressing MM, which is observed in up to $11 \%$ of MM patients (12). As another pitfall, diffuse skeletal involvement or decreased metabolic activity may reduce sensitivity (13). In addition, accurate scan interpretation can be hampered by ongoing inflammation, changes due to degenerative or inflammatory arthritis, or recent fractures-all sources of false positive uptake that potentially compromise the specificity of FDG (14). Other confounding factors include tumor heterogeneity and shifting pathophysiological pathways in advanced disease. In addition, the complexity of an FDG scan in MM patients may lead to inconsistent interpretation of imaging findings. To address this, Nanni et al. evaluated the Italian Myeloma criteria for PET USe (IMPeTUs) criteria (15). In brief, these are based on a visual assessment using the Deauville score and also include morphological findings of radiotracer distribution, e.g., non-focal uptake in the bone marrow or extramedullary lesions (16). IMPeTUs was reproducible for scans at baseline and during follow-up (15).

As such, the armamentarium of PET radiotracers for MM patients has been expanded to alternatives that are not dependent upon high glycolytic metabolism in the tumor cells. Options include, but are not limited to, $\left[{ }^{11} \mathrm{C}\right] /\left[{ }^{18} \mathrm{~F}\right]$ choline $(\mathrm{CH}),\left[{ }^{11} \mathrm{C}\right]$ methionine (MET), $\left[{ }^{68} \mathrm{Ga}\right]$ Pentixafor (PEN), $\left[{ }^{18} \mathrm{~F}\right]-$ $3^{\prime}$-fluoro- $3^{\prime}$-deoxythymidine (FLT) and $\left[{ }^{18} \mathrm{~F}\right]$-Sodium Fluoride (NaF) (17-23). In this focused review, novel imaging agents along with their theranostic potential in the context of MM will be highlighted.

\section{NOVEL RADIOTRACERS $\left[{ }^{68} \mathrm{Ga}\right]$ Pentixafor (PEN)}

The C-X-C motif chemokine receptor 4 (CXCR4) can be found in more than 30 different hematopoietic and solid cancers (24-27). In patients with MM, it is involved in homing and, cell mobilization from the bone marrow, potentially leading to distant organ involvement (28). In MM, about half of patients demonstrated distinct CXCR4 overexpression (29, 30), thereby rendering this receptor suitable for both imaging and therapy.

In this regard, the ${ }^{68} \mathrm{Ga}$-labeled radiotracer PEN allows for assessing the expression levels of the receptor in vivo (31) and thus, has been investigated in various clinical settings (32). For instance, Lapa et al. evaluated the diagnostic potential of this novel radiotracer through a study of 35 heavily pretreated MM patients (33). In $>65 \%$ of the cases, PEN identified CXCR4expression at putative sites of disease, independent of clinical parameters such as MM subtype, cytogenetics, or serological findings. Its prognostic value was also evaluated, demonstrating that shortened time-to-progress and time-to-death were linked to CXCR4-positive lesions. In addition, a head-to-head comparison with FDG revealed an equal number of lesions in $42 \%$ of the cases, whereas in $>20 \%$, PEN was superior when compared to the reference radiotracer (33) (Figure 1).

Those retrospective results were further corroborated prospectively by Pan et al. recruiting 30 newly diagnosed MM patients who also underwent dual-radiotracer imaging with PEN and FDG (34). 28/30 (93.3\%) patients had CXCR4-positive findings, while $16 / 30$ (53.3\%) patients had avidity on FDG PET, supporting the notion that PEN may identify additional sites of disease. Moreover, the authors reported on an association of PEN uptake with various clinical parameters, e.g., end organ damage or laboratory values reflecting tumor burden. For FDG, those correlations were less pronounced, further emphasizing the potential clinical value of PEN for a more precise reflection of disease extent (34).

Such promising results were recently expanded by Kuyumcu et al., who enrolled $24 \mathrm{MM}$ patients to investigate the predictive performance of PEN (35). In line with existing literature, increasing PET-based CXCR4 positivity was linked to reduced overall survival, an observation that was more pronounced than the correlation of FDG with that parameter (35).

Beyond its potential to overcome current limitations of FDG and its superior potential for risk stratification, PEN also allows the identification of patients eligible for treatment with CXCR4targeted agents, the so called theranostic approach. As such, after CXCR4 expression in MM patients in vivo has been established by PET, the $\left[{ }^{177} \mathrm{Lu}\right] /\left[{ }^{90} \mathrm{Y}\right]$-labeled analog Pentixather can be administered intravenously for endoradiotherapy. Extensive preclinical and first-in-human studies (36), revealed remarkable response rates, even in advanced disease $(37,38)$, along with tolerable side effects (39). In those patients, $\left[{ }^{177} \mathrm{Lu}\right]$ Pentixather dosimetry was conducted prior to treatment onset to assess the appropriate amount of activity to be injected during therapy (Figure 2). As this therapeutic approach inevitably leads to bone marrow ablation, subsequent hematopoetic stem cell transplantation is necessary (37). The concept of PET-based imaging and therapy with PEN/ $\left[{ }^{177} \mathrm{Lu}\right]$ Pentixather will also be further evaluated in the phase I/II COLPRIT trial (40).

\section{$\left[{ }^{11} \mathrm{C}\right]$ Methionine (MET)}

Immunoglobulins produced by myeloma cells also offer a potential as a molecular imaging target. In this regard, rapid internalization of L-amino acids into MM cells for the synthesis of immunoglobulins suggested MET as an alternative radiotracer in MM patients (41-43). In a study of 19 subjects with MM, Nakamoto et al. performed a dual-radiotracer study by using MET and FDG prior to treatment and for restaging (44). MET had a higher accuracy of $93 \%$ when compared to FDG (86\%), along with a greater number of MET-positive lesions, 

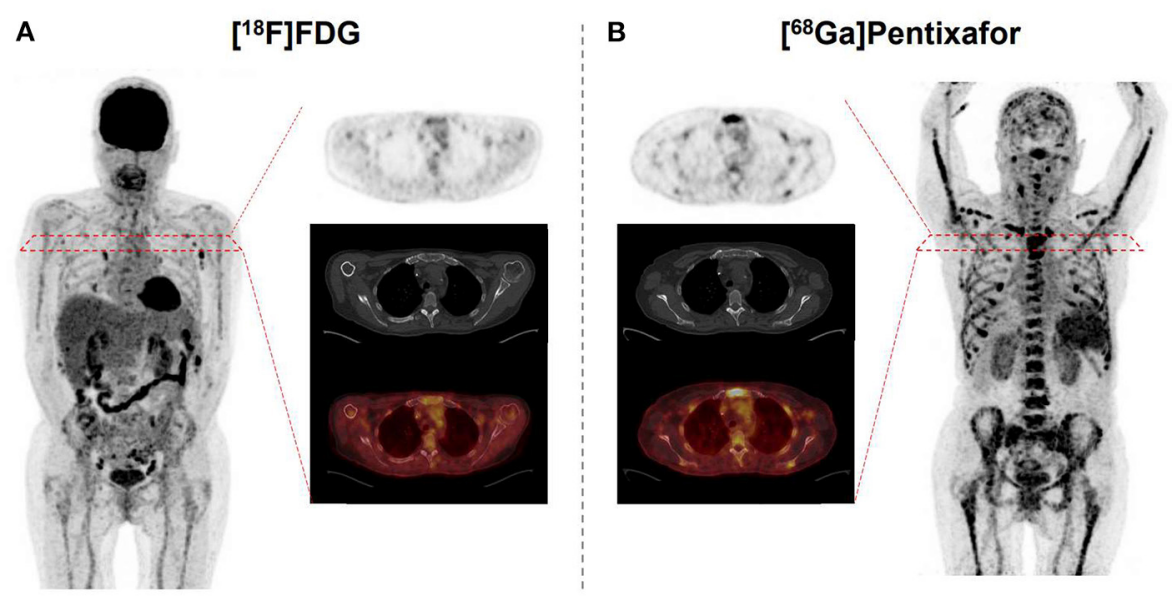

FIGURE 1 | 67 year-old patient afflicted with multiple myeloma. Relative to [ $\left.{ }^{18} \mathrm{~F}\right]$ fluorodeoxyglucose (FDG) (A), C-X-C motif chemokine receptor (CXCR4)-targeted $\left[{ }^{68} \mathrm{Ga}\right]$ Pentixafor $\mathbf{( B )}$ reveals more sites of disease, as displayed on both the maximum intensity projection and transaxial slices of PET (top) and PET/CT (bottom). Standardized uptake values range from 0 to 5 on both PETs.

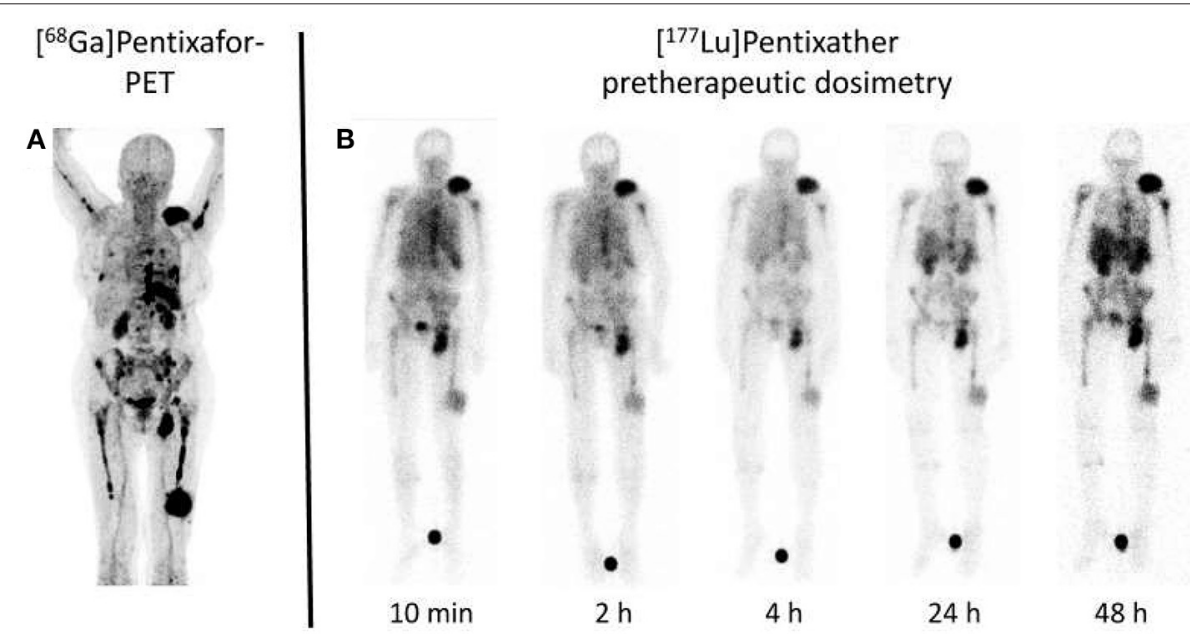

FIGURE 2 | Dosimetry approach for C-X-C motif chemokine receptor (CXCR4) directed treatment. (A) Maximum intensity projection of [68 Ga]Pentixafor PET in a multiple myeloma subject reveals multiple sites of both intra- and extramedullary disease involvement. (B) After injection of a small dosimetric activity of the therapeutic equivalent [ $\left.{ }^{177} \mathrm{Lu}\right]$ Pentixather $(200 \mathrm{MBq})$, scintigraphy obtained at up to $48 \mathrm{~h}$ post-injection reveals long-lasting radiotracer accumulation at relevant sites of disease. Such an approach not only allows to assess myeloma doses in a therapeutic setting, but also provides an estimate of doses to the kidneys as organs of risk, thereby minimizing off-target effects. Modified from Lapa et al. (38).

supporting the notion that MET may be superior for inconclusive findings obtained by FDG or for MM patients not adequately covered by conventional imaging (44). Further characterizing the clinical value of MET relative to FDG, Lapa et al. investigated newly diagnosed (11/43) and pretreated (32/43) MM patients by imaging with both FDG and MET (20) (Figures 3, 4). MET PET detected MM lesions in 39/43 (90.7\%) patients, whereas PET with FDG was considered positive only in 33/43 (76.7\%) of the subjects. In addition, MET PET revealed more focal intra- and extra-medullary lesions in 28/43 (65.1\%) patients. The extent of bone marrow infiltration, which was confirmed histologically in 32 patients, positively correlated with both MET and FDG uptake, which was more pronounced for the amino acid radiotracer (20).
Those promising results were further corroborated in a follow-up study that pooled 78 patients with MM from two different centers in Germany and Spain. A direct FDG/MET comparison revealed that active sites of disease would have been missed in $12 / 78$ (15.3\%) patients if only FDG would have been used (45). To provide evidence on the superior specificity of MET relative to FDG, biopsy was conducted in two patients, and the histology was concordant with MET findings $[\mathrm{FDG}(+) / \mathrm{MET}(-)$ demonstrating no plasma cell infiltration vs. Case \#2, $\operatorname{FDG}(-) / \mathrm{MET}(+)$ having infiltration of clonal plasma cells] (45). As such, MET may replace FDG as current reference for molecular imaging in MM patients (45). PET-based semiquantitative parameters were also assessed and, relative to FDG, MET-derived image biomarkers demonstrated a more 

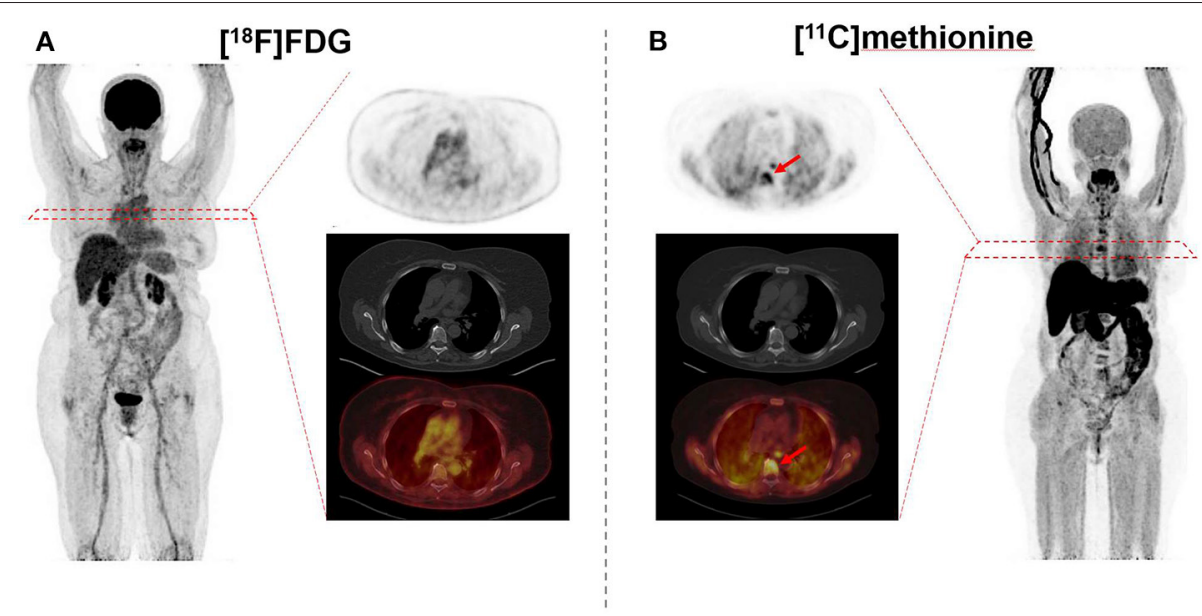

FIGURE 3 | 69 year-old female afflicted with multiple myeloma. Relative to $\left[{ }^{18} \mathrm{~F}\right]$ fluorodeoxyglucose (FDG) (A), $\left[{ }^{11}\right.$ C]methionine (B) reveals multiple intramedullary manifestations with intense uptake (arrows), as displayed on both the maximum intensity projection and transaxial slices of PET (top) and PET/CT (bottom). Standardized uptake values range from 0 to 5 on both PETs.

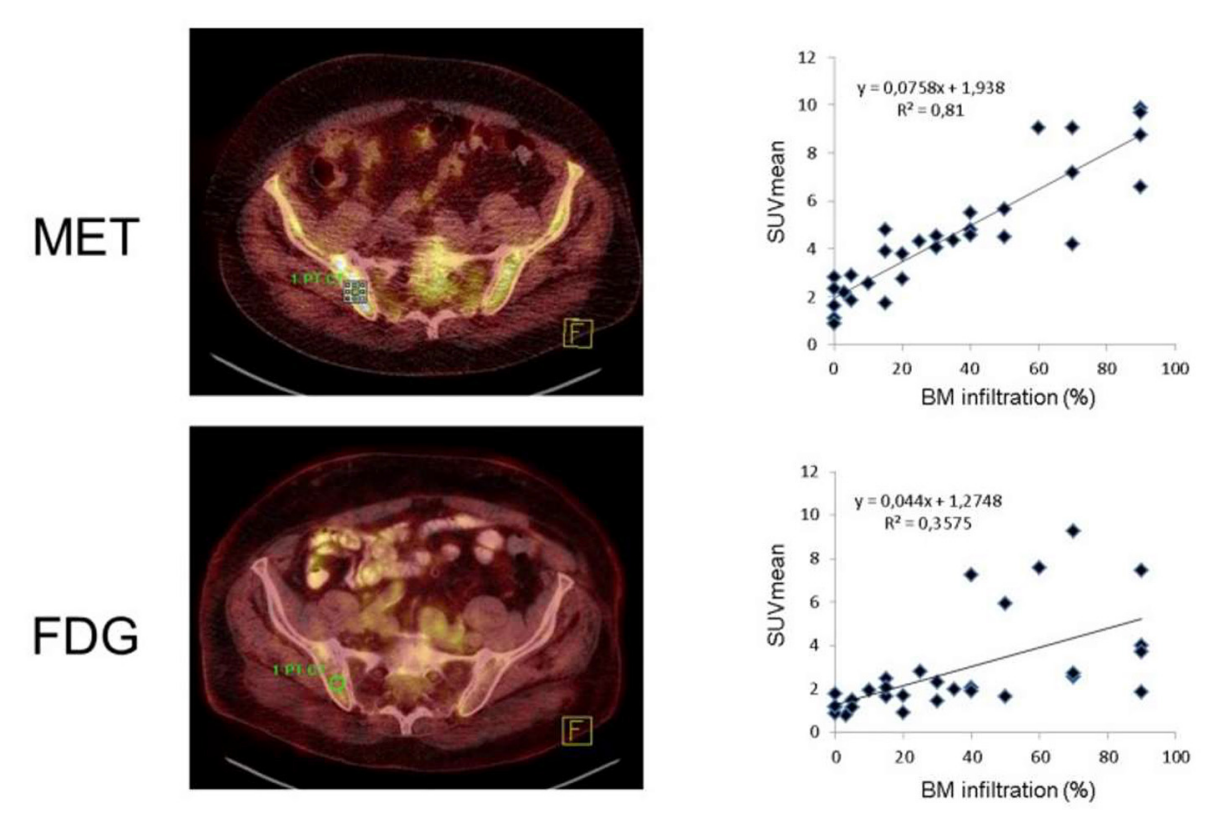

FIGURE 4 | Radiotracer uptake reveals a tight link with bone marrow infiltration, which was more pronounced for $\left[{ }^{11} \mathrm{C}\right]$ methionine (MET, top) than for $\left[{ }^{18} \mathrm{~F}\right.$ fluorodeoxyglucose (FDG, bottom). Bone marrow lesions identified by FDG and MET-PET (left). Right: Mean standardized uptake values (SUV mean) for all individuals $[n($ total $)=31]$ had a $r$ of 0.6 , while correlative index was even better for MET $(r=0.9)$. Modified from Lapa et al. (20).

substantial correlation with tumor burden, suggesting METbased PET quantification as a novel tool to identify high-risk individuals (46).

\section{$\left[{ }^{11} \mathrm{C}\right]$ Choline (CH)}

Choline has several physiological functions, including participation in cell growth and in the cell membrane synthesis as a component of phosphatidylcholine. The retention of choline is attributed to several uptake mechanisms. In cancer cells, including $\mathrm{MM}$ cells, uptake may be significantly increased compared to normal tissue due to the high replication rate and associated increased cell membrane turnover (47, 48). With approval of $\mathrm{CH}$ in individuals with prostate cancer, this tracer may be used more widely in the United States and Europe for investigating MM (49). Due to the 20 min half-life of $\left[{ }^{11} \mathrm{C}\right], \mathrm{CH}$ is limited to PET centers with access to an on-site cyclotron. Alternatively, $\mathrm{CH}$ can also be linked to $\left[{ }^{18} \mathrm{~F}\right]$, providing a half-life of $110 \mathrm{~min}$. However, robust data of a direct comparison 
between both radiotracers is still missing. In this regard, results of a currently recruiting trial investigating the performance of FDG relative to $\left[{ }^{18} \mathrm{~F}\right]$-choline are awaited (50). As results on $\left[{ }^{18} \mathrm{~F}\right]$-choline in $\mathrm{MM}$ are rather limited, we will focus on $\mathrm{CH}$.

Nanni et al. were the first conducting a comparison between $\mathrm{CH}$ and FDG in 10 patients with advanced $\mathrm{MM}$ at different disease stages, with a higher rate of bone lesions detected by $\mathrm{CH}$ relative to the reference radiotracer FDG (17). Based on these encouraging findings, Lapa et al. compared MET and $\mathrm{CH}$ in 19 subjects with MM (18/19) or solitary bone plasmacytoma $(1 / 19)$ (22). The authors demonstrated that MET was more accurate than $\mathrm{CH}$ to detect active MM lesions, along with an improved target-to-background ratio, and a substantial association between bone marrow involvement and MET accumulation (22).

Nonetheless, CH PET like MET PET is currently not applied to $\mathrm{MM}$ on a regular basis and may be further included in daily routine after having proven better accuracy in larger clinical trials. In this regard, 30 newly diagnosed MM patients will be evaluated by $\left[{ }^{18} \mathrm{~F}\right]$ fluorocholine and FDG in a currently recruiting study (51). This investigations aims to segregate between true- vs. false-positive PET lesions by comparing those scans with whole-body MRI (51), with the latter imaging modality known to be the reference for bone marrow lesions (52).

\section{$\left[{ }^{18} \mathrm{~F}\right]-3^{\prime}$-Fluoro-3'-Deoxythymidine (FLT)}

Interacting with cytosolic thymidine kinase (TK1) of the cell cycle, FLT represents a read-out of proliferating cells (53). The number of studies investigating FLT in the context of MM are limited. For instance, Sachpekidis et al. investigated FDG and FLT in eight MM subjects and found a total of 48 FDG positive lesions, while FLT identified 17 lesions. The latter radiotracer was also challenging for the assessment of lesions allocated to the bone marrow, mainly due to increased background (54).

\section{$\left[{ }^{18} \mathrm{~F}\right]$-Sodium Fluoride (NaF)}

$\mathrm{NaF}$ is widely utilized for assessment of bone involvement (55, 56). Not surprisingly, this radiotracer has also been applied to MM. Including 60 patients, FDG was compared to NaF and the latter radiotracer identified significantly less lesions attributable to MM (FDG, 343 vs. NaF, 135) (57). Those findings were further corroborated in a recent study assessing treatment response in MM patients after chemotherapy and stem cell transplantation. Of $129 \mathrm{FDG}(+)$ lesions, the bone-seeking radiopharmaceutical identified approximately half sites of disease. Taken together, the authors concluded on a limited role of $\mathrm{NaF}$ for assessing therapeutic efficacy (58).

\section{FUTURE PERSPECTIVES}

Given already favorable results of PEN imaging in patients with MM (38), the recent introduction of novel, second-generation CXCR4-directed radiotracers may improve efficacy along with prolonged tumor retention, thereby allowing for better image contrast, increased lesion detection rate, and even improved outcome (59) for therapeutic agents.

In addition, direct comparison of CXCR4-targeted radiotracers to $\mathrm{MET}$, e.g., to reveal complementary information or further insights into complex tumor heterogeneity in advanced disease, should be a goal of the field moving forward. This has already been conducted in smoldering MM by comparing FDG, MET and (first-generation radiotracer) PEN, with the latter agents MET and PEN being more accurate in detecting bone marrow involvement. Given these encouraging results, such triple-tracer approaches could be expanded toward other clinical scenarios, e.g., to identify high-risk smoldering MM patients eligible for clinical trials (60).

The high sensitivity of MET might prove especially clinically useful for residual disease, while FDG has demonstrated substantial value in addition to bone marrow based approaches (6).

In recent years, hybrid devices including PET and magnetic resonance imaging (MRI) have been installed. In cancer patients, Beiderwellen et al. were among the first to report on an improved read-out of bone lesions using PET/MRI when compared to PET/CT (61). Based on these encouraging results, $30 \mathrm{MM}$ patients were investigated using PET/MRI and PET/CT. After FDG injection, there were no relevant differences on a visual and quantitative assessment between both imaging modalities, with more than $94 \%$ of sites of disease identified both on PET/CT and PET/MRI. Future studies may further determine the usefulness of PET/MRI in MM patients, e.g., to assess treatment response (62).

Last, future studies should also investigate the potential of machine learning in the context of molecular imaging for MM patients, potentially increasing diagnostic accuracy (63). Such an approach may also allow for better identification of individuals who might benefit from a CXCR4-targeted radiolabeled therapeutic intervention or could allow the identification of high-risk individuals prone to off-target effects, e.g., in the kidneys (39).

\section{CONCLUSION}

Considered the work-horse for molecular imaging in $\mathrm{MM}$ patients, FDG is endorsed by current guidelines for clinical situations such as response monitoring. The inherent limitations of this radiotracer have triggered the development of (novel) alternative PET radiopharmaceuticals. Among others, the CXCR4-targeted agent PEN, the amino acid radiotracer MET and $\mathrm{CH}$ have been extensively investigated, demonstrating increased sensitivity and specificity when compared to FDG. Of note, PEN also paves the way to select candidates for a theranostic approach, offering a rationale for CXCR4-based endoradiotherapy in advanced disease. Further studies are needed, e.g., evaluating PEN and MET in a prospective setting and to prove their clinical impact on therapeutic decisions, as well as to establish improved algorithms to identify subjects who might benefit from CXCR4targeted radiolabeled therapy by minimizing off-target effects.

\section{AUTHOR CONTRIBUTIONS}

All authors contributed in drafting, revising, and proofreading the manuscript. 


\section{REFERENCES}

1. Swerdlow SH, Campo E, Harris NL, Jaffe ES, Pileri SA, Stein H, et al. WHO Classification of Tumours of Haematopoietic and Lymphoid Tissues. Revised 4th Edition, Geneva, World Health Organization (2017).

2. Kazandjian D. Multiple myeloma epidemiology and survival: a unique malignancy. Semin Oncol. (2016) 43:676-81. doi: 10.1053/j.seminoncol.2016.11.004

3. Collins CD. Problems monitoring response in multiple myeloma. Cancer Imaging. (2005) 5:S119-26. doi: 10.1102/1470-7330.2005.0033

4. Rajkumar SV, Dimopoulos MA, Palumbo A, Blade J, Merlini G, Mateos $\mathrm{M}-\mathrm{V}$, et al. International Myeloma Working Group updated criteria for the diagnosis of multiple myeloma. Lancet Oncol. (2014) 15:e538-48. doi: 10.1016/S1470-2045(14)70442-5

5. Hillengass J, Usmani S, Rajkumar SV, Durie BGM, Mateos M-V, Lonial S, et al. International myeloma working group consensus recommendations on imaging in monoclonal plasma cell disorders. Lancet Oncol. (2019) 20:e30212. doi: 10.1016/S1470-2045(19)30309-2

6. Moreau P, Attal M, Caillot D, Macro M, Karlin L, Garderet L, et al. Prospective evaluation of magnetic resonance imaging and [18F]Fluorodeoxyglucose positron emission tomography-computed tomography at diagnosis and before maintenance therapy in symptomatic patients with multiple myeloma included in the IFM/DFCI 2009 trial: results of the IMAJEM study. J Clin Oncol. (2017) 35:2911-8. doi: 10.1200/JCO.2017.72.2975

7. Terpos E, Dimopoulos MA, Moulopoulos LA. The role of imaging in the treatment of patients with multiple myeloma in 2016. Am Soc Clin Oncol Educ Book. (2016) 35:e407-17. doi: 10.1200/EDBK_159074

8. Jamet B, Zamagni E, Nanni C, Bailly C, Carlier T, Touzeau C, et al. Functional imaging for therapeutic assessment and minimal residual disease detection in multiple Myeloma. Int J Mol Sci. (2020) 21:5406. doi: 10.3390/ijms21155406

9. Cavo M, Terpos E, Nanni C, Moreau P, Lentzsch S, Zweegman S, et al. Role of 18F-FDG PET/CT in the diagnosis and management of multiple myeloma and other plasma cell disorders: a consensus statement by the International Myeloma Working Group. Lancet Oncol. (2017) 18:e206-17. doi: 10.1016/S1470-2045(17)30189-4

10. Zamagni E, Patriarca F, Nanni C, Zannetti B, Englaro E, Pezzi A, et al. Prognostic relevance of 18-F FDG PET/CT in newly diagnosed multiple myeloma patients treated with up-front autologous transplantation. Blood. (2011) 118:5989-95. doi: 10.1182/blood-2011-06-361386

11. Sachpekidis C, Merz M, Kopp-Schneider A, Jauch A, Raab M-S, Sauer S, et al. Quantitative dynamic 18F-fluorodeoxyglucose positron emission tomography/computed tomography before autologous stem cell transplantation predicts survival in multiple myeloma. Haematologica. (2019) 104:e420-3. doi: 10.3324/haematol.2018.213041

12. Rasche L, Angtuaco E, McDonald JE, Buros A, Stein C, Pawlyn C, et al. Low expression of hexokinase-2 is associated with false-negative FDGpositron emission tomography in multiple myeloma. Blood. (2017) 130:30-4. doi: 10.1182/blood-2017-03-774422

13. Terpos E, Moulopoulos LA, Dimopoulos MA. Advances in imaging and the management of myeloma bone disease. J Clin Oncol. (2011) 29:1907-15. doi: 10.1200/JCO.2010.32.5449

14. Matteucci F, Paganelli G, Martinelli G, Cerchione C. PET/CT in multiple myeloma: beyond FDG. Front Oncol. (2021) 10:622501. doi: $10.3389 /$ fonc.2020.622501

15. Nanni C, Versari A, Chauvie S, Bertone E, Bianchi A, Rensi M, et al. Interpretation criteria for FDG PET/CT in multiple myeloma (IMPeTUs): final results. IMPeTUs (Italian myeloma criteria for PET USe). Eur J Nucl Med Mol Imaging. (2018) 45:712-9. doi: 10.1007/s00259-0173909-8

16. Nanni C, Zamagni E, Versari A, Chauvie S, Bianchi A, Rensi M, et al. Image interpretation criteria for FDG PET/CT in multiple myeloma: a new proposal from an Italian expert panel. IMPeTUs (Italian Myeloma criteria for PET USe). Eur J Nucl Med Mol Imaging. (2016) 43:414-21. doi: 10.1007/s00259-015-3200-9

17. Nanni C, Zamagni E, Cavo M, Rubello D, Tacchetti P, Pettinato C, et al. 11C-choline vs. 18F-FDG PET/CT in assessing bone involvement in patients with multiple myeloma. World J Surg Oncol. (2007) 5:68. doi: $10.1186 / 1477-7819-5-68$
18. Philipp-Abbrederis K, Herrmann K, Schottelius M, Eiber M, Gerngroß C, Pietschmann E, et al. [68Ga]Pentixafor: A novel PET tracer for imaging CXCR4 status in patients with multiple myeloma. Blood. (2014) 124:2014. doi: 10.1182/blood.V124.21.2014.2014

19. Cassou-Mounat T, Balogova S, Nataf V, Calzada M, Huchet V, Kerrou $\mathrm{K}$, et al. 18F-fluorocholine versus 18F-fluorodeoxyglucose for PET/CT imaging in patients with suspected relapsing or progressive multiple myeloma: a pilot study. Eur J Nucl Med Mol Imaging. (2016) 43:1995-2004. doi: 10.1007/s00259-016-3392-7

20. Lapa C, Knop S, Schreder M, Rudelius M, Knott M, Jörg G, et al. 11C-Methionine-PET in multiple myeloma: correlation with clinical parameters and bone marrow involvement. Theranostics. (2016) 6:254-61. doi: $10.7150 /$ thno. 13921

21. Lapa C, Schreder M, Lückerath K, Samnick S, Rudelius M, Buck AK, et al. [11C]Methionine emerges as a new biomarker for tracking active myeloma lesions. Br J Haematol. (2018) 181:701-3. doi: 10.1111/bjh.14696

22. Lapa C, Kircher M, Da Via M, Schreder M, Rasche L, Kortüm $\mathrm{KM}$, et al. Comparison of 11C-Choline and 11C-Methionine PET/CT in multiple myeloma. Clin Nucl Med. (2019) 44:620-4. doi: 10.1097/RLU.0000000000002638

23. Sachpekidis C, Goldschmidt H, Dimitrakopoulou-Strauss A. Positron emission tomography (PET) radiopharmaceuticals in multiple myeloma. Molecules. (2019) 25:E134. doi: 10.3390/molecules25010134

24. Burger JA, Kipps TJ. CXCR4: a key receptor in the crosstalk between tumor cells and their microenvironment. Blood. (2006) 107:1761-7. doi: 10.1182/blood-2005-08-3182

25. Burger JA, Peled A. CXCR4 antagonists: targeting the microenvironment in leukemia and other cancers. Leukemia. (2009) 23:43-52. doi: 10.1038/leu.2008.299

26. Zhang B, Wu T, Wang Z, Zhang Y, Wang J, Yang B, et al. p38MAPK activation mediates tumor necrosis factor- $\alpha$-induced apoptosis in glioma cells. Mol Med Rep. (2015) 11:3101-7. doi: 10.3892/mmr.2014.3002

27. Müller A, Homey B, Soto H, Ge N, Catron D, Buchanan ME, et al. Involvement of chemokine receptors in breast cancer metastasis. Nature. (2001) 410:50-6. doi: 10.1038/35065016

28. Ullah TR. The role of CXCR4 in multiple myeloma: Cells' journey from bone marrow to beyond. J Bone Oncol. (2019) 17:100253. doi: 10.1016/j.jbo.2019.100253

29. Bao L, Lai Y, Liu Y, Qin Y, Zhao X, Lu X, et al. CXCR4 is a good survival prognostic indicator in multiple myeloma patients. Leuk Res. (2013) 37:10838. doi: 10.1016/j.leukres.2013.06.002

30. Philipp-Abbrederis K, Herrmann K, Knop S, Schottelius M, Eiber M, Lückerath $\mathrm{K}$, et al. In vivo molecular imaging of chemokine receptor CXCR4 expression in patients with advanced multiple myeloma. EMBO Mol Med. (2015) 7:477-87. doi: 10.15252/emmm.201404698

31. Wester HJ, Keller U, Schottelius M, Beer A, Philipp-Abbrederis K, Hoffmann F, et al. Disclosing the CXCR4 expression in lymphoproliferative diseases by targeted molecular imaging. Theranostics. (2015) 5:618-30. doi: $10.7150 /$ thno. 11251

32. Kircher M, Herhaus P, Schottelius M, Buck AK, Werner RA, Wester H-J, et al. CXCR4-directed theranostics in oncology and inflammation. Ann Nucl Med. (2018) 32:503-11. doi: 10.1007/s12149-018-1290-8

33. Lapa C, Schreder M, Schirbel A, Samnick S, Kortüm KM, Herrmann K, et al. [68Ga]Pentixafor-PET/CT for imaging of chemokine receptor CXCR4 expression in multiple myeloma - Comparison to [18F]FDG and laboratory values. Theranostics. (2017) 7:205-12. doi: 10.7150/thno.16576

34. Pan Q, Cao X, Luo Y, Li J, Feng J, Li F. Chemokine receptor-4 targeted PET/CT with 68Ga-Pentixafor in assessment of newly diagnosed multiple myeloma: comparison to 18F-FDG PET/CT. Eur J Nucl Med Mol Imaging. (2020) 47:537-46. doi: 10.1007/s00259-019-04605-z

35. Kuyumcu S, Isik EG, Tiryaki TO, Has-Simsek D, Sanli Y, Buyukkaya F, et al. Prognostic significance of 68Ga-Pentixafor PET/CT in multiple myeloma recurrence: a comparison to $18 \mathrm{~F}-\mathrm{FDG}$ PET/CT and laboratory results. Ann Nucl Med. (2021) 35:1147-56. doi: 10.1007/s12149-021-01652-1

36. Schottelius M, Osl T, Poschenrieder A, Hoffmann F, Beykan S, Hänscheid H, et al. [177Lu] pentixather: comprehensive preclinical characterization of a First CXCR4-directed endoradiotherapeutic agent. Theranostics. (2017) 7:2350-62. doi: $10.7150 /$ thno. 19119 
37. Herrmann K, Schottelius M, Lapa C, Osl T, Poschenrieder A, Hänscheid H, et al. First-in-human experience of CXCR4-directed endoradiotherapy with $177 \mathrm{Lu}$ - and 90Y-labeled pentixather in advanced-stage multiple myeloma with extensive intra- and extramedullary disease. J Nucl Med. (2016) 57:248-51. doi: 10.2967/jnumed.115.167361

38. Lapa C, Herrmann K, Schirbel A, Hänscheid H, Lückerath K, Schottelius $\mathrm{M}$, et al. CXCR4-directed endoradiotherapy induces high response rates in extramedullary relapsed Multiple Myeloma. Theranostics. (2017) 7:1589-97. doi: 10.7150/thno.19050

39. Maurer S, Herhaus P, Lippenmeyer R, Hänscheid H, Kircher M, Schirbel A, et al. Side effects of CXC-chemokine receptor 4-directed endoradiotherapy with pentixather before hematopoietic stem cell transplantation. J Nucl Med. (2019) 60:1399-405. doi: 10.2967/jnumed.118.223420

40. Lapa C, Hänscheid H, Kortüm KM, Wester H-J, Buck A. CXCR4gerichtete Endoradiotherapie von hämatologischen Erkrankungen. Der Nuklearmediziner. (2019) 42:36-45. doi: 10.1055/a-0807-3512

41. Hammerton K, Cooper DA, Duckett M, Penny R. Biosynthesis of immunoglobulin in human immunoproliferative diseases. I. Kinetics of synthesis and secretion of immunoglobulin and protein by bone marrow cells in myeloma. J Immunol. (1978) 121:409-17.

42. Dankerl A, Liebisch P, Glatting G, Friesen C, Blumstein N, Kocot D, et al. Multiple myeloma: molecular imaging with $11 \mathrm{C}$-Methionine PET/CT-initial experience 1. Radiology. (2007) 242:498-508. doi: 10.1148/radiol.2422051980

43. Lückerath K, Lapa C, Albert C, Herrmann K, Jörg G, Samnick S, et al. 11C-Methionine-PET: a novel and sensitive tool for monitoring of early response to treatment in multiple myeloma. Oncotarget. (2015) 6:8418-29. doi: 10.18632/oncotarget.3053

44. Nakamoto Y, Kurihara K, Nishizawa M, Yamashita K, Nakatani K, Kondo $\mathrm{T}$, et al. Clinical value of $11 \mathrm{C}$-methionine PET/CT in patients with plasma cell malignancy: comparison with 18F-FDG PET/CT. Eur J Nucl Med Mol Imaging. (2013) 40:708-15. doi: 10.1007/s00259-012-2333-3

45. Lapa C, Garcia-Velloso M, Lückerath K, Samnick S, Schreder M, Otero P, et al. 11 C-Methionine-PET in multiple myeloma: a combined study from two different institutions. Theranostics. (2017) 7:2956-64. doi: 10.7150/thno.20491

46. Morales-Lozano MI, Viering O, Samnick S, Rodriguez-Otero P, Buck AK, Marcos-Jubilar M, et al. 18F-FDG and 11C-Methionine PET/CT in newly diagnosed multiple myeloma patients: comparison of volume-based PET biomarkers. Cancers. (2020) 12:E1042. doi: 10.3390/cancers 12041042

47. Utriainen M, Komu M, Vuorinen V, Lehikoinen P, Sonninen P, Kurki T, et al. Evaluation of brain tumor metabolism with [11C]choline PET and 1H-MRS. J Neurooncol. (2003) 62:329-38. doi: 10.1023/A:1023342516925

48. Breeuwsma AJ, Pruim J, Jongen MM, Suurmeijer AJ, Vaalburg W, Nijman RJ, et al. In vivo uptake of [11C]choline does not correlate with cell proliferation in human prostate cancer. Eur J Nucl Med Mol Imaging. (2005) 32:668-73. doi: 10.1007/s00259-004-1741-4

49. FDA approves 11C-choline for PET in prostate cancer. J Nucl Med. (2012) 53:11N.

50. Mesguich C, Hulin C, Latrabe V, Asselineau J, Bordenave L, Perez $\mathrm{P}$, et al. Prospective comparison of $18 \mathrm{~F}$-choline positron emission tomography/computed tomography (PET/CT) and 18F-fluorodeoxyglucose (FDG) PET/CT in the initial workup of multiple myeloma: study protocol of a prospective imaging trial. JMIR Res Protoc. (2020) 9:e17850. doi: $10.2196 / 17850$

51. Mesguich C, Hulin C, Lascaux A, Bordenave L, Marit G, Hindié E. Choline PET/CT in multiple myeloma. Cancers. (2020) 12:E1394. doi: 10.3390/cancers12061394

52. Zamagni E, Tacchetti P, Cavo M. Imaging in multiple myeloma: How? When? Blood. (2019) 133:644-51. doi: 10.1182/blood-2018-08-825356

53. Peck M, Pollack HA, Friesen A, Muzi M, Shoner SC, Shankland EG, et al. Applications of PET imaging with the proliferation marker [18F]-FLT. Q J Nucl Med Mol Imaging. (2015) 59:95-104.
54. Sachpekidis C, Goldschmidt H, Kopka K, Kopp-Schneider A, Dimitrakopoulou-Strauss A. Assessment of glucose metabolism and cellular proliferation in multiple myeloma: a first report on combined 18F-FDG and 18F-FLT PET/CT imaging. EJNMMI Res. (2018) 8:28. doi: 10.1186/s13550-018-0383-7

55. Czernin J, Satyamurthy N, Schiepers C. Molecular mechanisms of bone 18F-NaF deposition. J Nucl Med. (2010) 51:1826-9. doi: 10.2967/jnumed.110.077933

56. Sheikhbahaei S, Jones KM, Werner RA, Salas-Fragomeni RA, Marcus $\mathrm{CV}$, Higuchi $\mathrm{T}$, et al. 18F-NaF-PET/CT for the detection of bone metastasis in prostate cancer: a meta-analysis of diagnostic accuracy studies. Ann Nucl Med. (2019) 33:351-61. doi: 10.1007/s12149-01901343-y

57. Sachpekidis C, Goldschmidt H, Hose D, Pan L, Cheng C, Kopka K, et al. PET/CT studies of multiple myeloma using (18) F-FDG and (18) F-NaF: comparison of distribution patterns and tracers' pharmacokinetics. Eur J Nucl Med Mol Imaging. (2014) 41:1343-53. doi: 10.1007/s00259-0142721-y

58. Sachpekidis C, Hillengass J, Goldschmidt H, Wagner B, Haberkorn U, Kopka K, et al. Treatment response evaluation with 18F-FDG PET/CT and 18F-NaF PET/CT in multiple myeloma patients undergoing high-dose chemotherapy and autologous stem cell transplantation. Eur J Nucl Med Mol Imaging. (2017) 44:50-62. doi: 10.1007/s00259-0163502-6

59. Osl T, Schmidt A, Schwaiger M, Schottelius M, Wester H-J. A new class of PentixaFor- and PentixaTher-based theranostic agents with enhanced CXCR4-targeting efficiency. Theranostics. (2020) 10:8264-80. doi: 10.7150/thno.45537

60. Zhou X, Dierks A, Kertels O, Kircher M, Schirbel A, Samnick S, et al. 18F-FDG, 11C-Methionine, and 68Ga-Pentixafor PET/CT in patients with smoldering multiple myeloma: imaging pattern and clinical features. Cancers. (2020) 12:E2333. doi: 10.3390/cancers 12082333

61. Beiderwellen K, Huebner M, Heusch P, Grueneisen J, Ruhlmann V, Nensa F, et al. Whole-body $\left[{ }^{18} \mathrm{~F}\right] \mathrm{FDG}$ PET/MRI vs. PET/CT in the assessment of bone lesions in oncological patients: initial results. Eur Radiol. (2014) 24:2023-30. doi: 10.1007/s00330-014-3229-3

62. Sachpekidis C, Hillengass J, Goldschmidt H, Mosebach J, Pan L, Schlemmer $\mathrm{H}-\mathrm{P}$, et al. Comparison of (18)F-FDG PET/CT and PET/MRI in patients with multiple myeloma. Am J Nucl Med Mol Imaging. (2015) 5:469-78. doi: 10.1097/RLU.0000000000000773

63. Koshino K, Werner RA, Pomper MG, Bundschuh RA, Toriumi F, Higuchi $\mathrm{T}$, et al. Narrative review of generative adversarial networks in medical and molecular imaging. Ann Transl Med. (2021) 9:821. doi: 10.21037/atm-20-6325

Conflict of Interest: The authors declare that the research was conducted in the absence of any commercial or financial relationships that could be construed as a potential conflict of interest.

Publisher's Note: All claims expressed in this article are solely those of the authors and do not necessarily represent those of their affiliated organizations, or those of the publisher, the editors and the reviewers. Any product that may be evaluated in this article, or claim that may be made by its manufacturer, is not guaranteed or endorsed by the publisher.

Copyright (C) 2022 von Hinten, Kircher, Dierks, Pfob, Higuchi, Pomper, Rowe, Buck, Samnick, Werner and Lapa. This is an open-access article distributed under the terms of the Creative Commons Attribution License (CC BY). The use, distribution or reproduction in other forums is permitted, provided the original author(s) and the copyright owner(s) are credited and that the original publication in this journal is cited, in accordance with accepted academic practice. No use, distribution or reproduction is permitted which does not comply with these terms. 